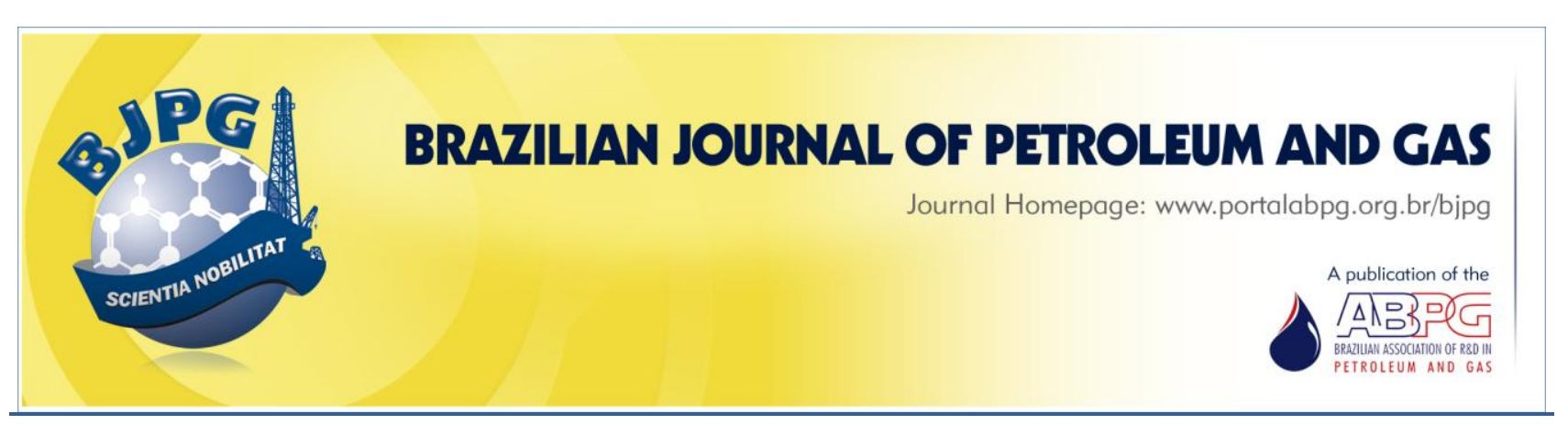

\title{
METHOD TO EVALUATE FOAMING IN PETROLEUM
}

\author{
${ }^{\text {a }}$ Fraga, A. K.; ${ }^{\text {a }}$ Rezende, D. A.; ${ }^{\text {a }}$ Santos, R. F.; ${ }^{\text {a }}$ Mansur, C. R. E. ${ }^{1}$ \\ ${ }^{\text {a }}$ Federal University of Rio de Janeiro - Macromolecules Institute
}

\begin{abstract}
In oilfields, gravitational separation tanks are generally used to separate the oil, gas and water phases, remove emulsifying agents present at the interfaces and permit the coalescence of water droplets associated with the crude oil being pumped. The main problem that influences the performance of these separators is the formation of foam. In this work, a method was developed to evaluate foaming in crude oil in laboratory scale, reproducing the operation conditions in gas-oil separators in real fields. This method was employed with seven crude oil samples, and the performance of silicone antifoams with different molar masses could be tested. The results indicated that the method of evaluating the breakdown of foam in oil by using the Aging Cell apparatus in a roller oven proved to be suitable. It was observed that the oil viscosity is a determining factor in predicting whether or not foam will form.
\end{abstract}

\section{KEYWORDS}

Antifoams; petroleum; silicones; gas-oil separators; surface tension

\footnotetext{
${ }^{1}$ To whom all correspondence should be addressed. Address: Federal University of Rio de Janeiro, Macromolecules Institute, Av. Horácio Macedo, 2030 - Ilha do Fundão, 21941598, Rio de Janeiro, RJ, Brazil Telephone: +55 21 2562-7209 | e-mail:celias@ima.ufri.br doi:10.5419/bjpg2011-0004
} 


\section{INTRODUCTION}

In oilfields, gravitational separation tanks are generally used to separate the oil, gas and water phases, remove emulsifying agents present at the phase interfaces and permit the coalescence of water droplets associated with the crude oil being pumped. Although there are many factors that influence the performance of these separators, the main problem is the formation of foam, in that it hampers mechanical control of the liquid and can lead to spills from tanks and equipment. Moreover, foam takes up space in the tanks, reduces the separation capacity and efficiency, and increases the drag of the liquid phase within the gas phase and vice versa, sometimes to the point of requiring shutdowns of the process (Chilingarian et al., 1987).

One of the ways to prevent foaming is to modify the separator design. But this is often unfeasible because of the limited space on many offshore platforms. Therefore, chemical additives known as antifoams or foam inhibitors are employed to prevent or break up the foam. This method can be improved by having more detailed knowledge of the components present in the petroleum and their contributions to its properties (Szilas, 1986).

Significant advances have been made in understanding the role played by the different components of crude oil (such as asphaltenes and resins), their percentages, elementary composition and molar masses, both in stabilizing emulsions and foams. These fluid components give rise to emulsions and the formation of foam upon being subjected to agitation and shear forces in the presence of predominantly lipophilic natural surfactants present in the oil (asphaltenes, resins, naphthenic acids, among other chemical species) (Poindexter et al., 2002; Shaban, 1995).

With respect to the specific components of crude oil, Callaghan et al. (1985) demonstrated that various surfactants are naturally found among these components, especially those with short carboxylic acid chains and phenols with molar mass of up to 400 , which can stabilize the foam.

Other researchers (Musser and Kilpatrick, 1998; Poindexter et al., 2002) have shown that species such as asphaltenes, resins or waxes tend to stabilized foam by increasing the oil viscosity.
By relying on various oilfield production data, Mclean et al. (1995) proposed a model whereby the asphaltenes and resins in certain oils are absorbed within the gas bubbles when the pressure falls below the bubble point. As a result, a semi-rigid coating is formed, causing the foam to stabilize and the viscosity to decline.

Injection of silicone in gravitational separators has been used for many years to control foam (Pape, 1983). The objective of this work was to develop a novel method to evaluate foaming in crude oil and the destruction of foam with antifoams that are already commonly used.

\section{EXPERIMENTAL}

\subsection{Materials}

Three samples of silicone foam inhibitors, with different molar masses, donated by Bluestar Silicones, SP (Brazil) were evaluated. All samples were used as received, and were named as S1, S2 and S3.

The formulations containing the antifoams were prepared by dissolving the samples in the commercial solvent Solbrax Eco, donated by BR Distribuidora, a subsidiary of Petrobras (Brazil). According to the manufacturer's specifications (Solbrax Eco Solvent, 2008), the product mainly consists of a mixture of aliphatic and naphthenic hydrocarbons, with less than $1 \%$ aromatics (obtained by catalytic hydrogenation, which permits converting the aromatics into naphthenes, reducing the sulfur content, saturating the olefins and eliminating polar impurities). Also according to the manufacturer, this process allows obtaining a highly stable solvent, with only a slight odor and low toxicity. For these reasons, there is interest in using it as a solvent in formulations employed in oilfields.

To evaluate the efficiency of the foam inhibitors, solutions of $30 \% \mathrm{wt} / \mathrm{vol}$ of each additive were prepared. From these solutions, aliquots were collected at previously calculated amounts, and then added to the oil samples in order to contain the desired concentration of additive in each system, so that all assays could be properly conducted. 
The chemical composition of the samples of silicone and Solbrax Eco solvent were determined through carbon-13 nuclear magnetic resonance $\left({ }^{13} \mathrm{C}\right.$-NMR). The samples were placed without any preparation or dissolution in a 10-mm OD test tube containing a capillary with an adequate deuterated solvent, so as not to coincide with the probable signs of the sample. The acquisition parameters of the analyses were determined under the standard conditions established by the device's maker, and the sample was maintained at a temperature of 30 ${ }^{\circ} \mathrm{C}$ while obtaining the spectra.

Quantitative analyses were performed to identify the structure of the silicone samples, as well as to determine their compositions, by the conventional calculation method based on the principle that the area under each peak is directly proportional to the number of carbon-13 nuclei of that region. The peak areas were calculated by an integrator coupled to the device.

Seven Brazilian crude oil samples were used, donated by the Petrobras Research Center (Cenpes). The samples were characterized regarding their densities, determined in an Anton Paar DMA 5000 digital density meter. The procedure to quantify the density of the oil samples was based on the ASTM D 4052 method (2009), using an oscillating U-tube sensor to measure the density. Their levels of saturated hydrocarbons, total aromatic hydrocarbons, resins and asphaltenes were determined by the SARA method by means of thin-layer chromatography (TLC) with a flame ionization detector (FID), to obtain the chemical composition of each oil (Ramalho et al., 2010).

The viscosity of the oil samples was determined in a Haake RS 600 rheometer, using a $\mathrm{C} 20 / 1^{\circ} \mathrm{Ti}$ cone-plate. The analyses were performed at a shear rate interval between 30 and $80 \mathrm{~s}^{-1}$, at a temperature of $60^{\circ} \mathrm{C}$.

\subsection{Methods}

\subsubsection{Determination of the surface tension of the oil samples}

The oil-air interfacial tensions were measured by the Du Nöuy method using a Krüss K10ST digital tensiometer, at $30^{\circ} \mathrm{C}$. Firstly, the oil samples were analyzed without adding any solvent. Then $2-\mu \mathrm{L}$ aliquots of the additive solutions, prepared with Solbrax at a concentration of $30 \% \mathrm{wt} / \mathrm{vol}$, were mixed in $15 \mathrm{~mL}$ of oil and the surface tension values of these systems were measured. All tests were run in triplicate.

\subsubsection{Testing the efficiency of the additives as antifoams}

Initially, the tests of foam formation in one of the oil samples (crude oil 2) were performed by varying some conditions in order to observe the influence of each one of them in the foam formation. A total of $150 \mathrm{~mL}$ of each oil sample was transferred to a compression cell (High Temperature Aging Cell, Fann). This cell was then sealed and connected to a compressed air line with a rubber hose. The chamber was pressurized to 50 , 200 and 250 psi, measured with a manometer, and held at each pressure for three minutes by shutting the ball valve.

The compression cell was placed in a Fann $704 \mathrm{Es}$ roller oven, preheated to 48 and $63^{\circ} \mathrm{C}$ (three degrees above the testing temperatures). The cell was then allowed to rotate at $50 \mathrm{rpm}$ for one and two hours.

At the end of these tests, the compression cell was connected to the decompression cell, in this case a $100-\mathrm{mL}$ graduated cylinder. It was placed vertically and the cell's outlet was kept pointing downward. Then the cell's valve was opened slightly and closed when the initial height of the foam formed inside the decompression cell reached $80 \mathrm{~mL}$. The time count started immediately after the valve was shut.

Later, the tests with the other six oil samples were performed following the same procedure and under the preselected conditions (pressure: 200 psi, temperature of $60{ }^{\circ} \mathrm{C}$ and conditioning time of 1 hour). Different aliquots of solutions containing $30 \% \mathrm{wt} / \mathrm{vol}$ of silicone-based antifoaming additives were added during the tests in order to evaluate the efficiency of these additives by the developed methodology.

The foam height was read at intervals of time until constant consecutive values were attained, indicating total break-up of the foam.

The percentage of foam formed in each interval was calculated with Equation 1. 
$\operatorname{Foam}(\% v / v)=\frac{H-H_{F}}{H_{F}} \times 100$

Where $H$ is the height reached by the foam on the scale at each time interval, and $H_{F}$ is the final height reached by the liquid after all the foam was destroyed. All tests were run in triplicate. The average values of formed foam (\%) and the standard deviation (SD) were added to the graphics.

\section{RESULTS AND DISCUSSIONS}

\subsection{Chemical characterization of the samples}

The ${ }^{13} \mathrm{C}-\mathrm{NMR}$ analysis of silicone sample $\mathrm{S} 1$ is shown in Figure 1. The spectra of the other samples showed the same chemical shifts observed in this spectrum, only differing in the intensity of the signals.

The structure of the commercial silicone analyzed is also shown in Figure 1 and was proposed based on findings in the literature (Silverstein et al., 1991) and the chemical shifts observed in the $\mathrm{NMR}^{-13} \mathrm{C}$ spectra. In particular, one has:

- Peak(s) at 1.687 ppm: attributed to the six methyl carbon atoms present at the ends of the chains;
- Peak(s) at 0.940 ppm: attributed to the two methyl carbon atoms located in the repeated unit of the chains;

- Peaks at 1.440 and 0.445 ppm: explained as side bands, which are distortions observed in high-intensity signals caused by a dispersion of the radiofrequency of an observed nucleus. They are more often observed in highly abundant nuclei, such as hydrogen, phosphorus and fluorine.

The molar mass of the commercial silicone samples was determined by integrating the areas under the signals acquired in the carbon-13 spectrum. For sample S1, the integration of the area under the signal located at $1.687 \mathrm{ppm}$ was equal to 5.04. Thus, since this signal was attributed to six carbon atoms, each methyl group corresponds to an integral value of 0.84 . With this information and the integral value of 94.18 corresponding to the two methyl groups of the repeated unit, it was possible to calculate the polymerization degree $(n)$ of this macromolecule, which is approximately 55 . Hence, the molar mass of sample $\mathrm{S} 1$ is $4,230 \mathrm{~g} / \mathrm{mol}$.

For sample S2, the areas under the spectrum signals were 0.58 for each of the six methyl groups at the ends of the chain and 98.36 for the two methyl groups of the repeated unit, implying an " $n$ " value of approximately 447 . Therefore, the molar mass is about $33,200 \mathrm{~g} / \mathrm{mol}$, which is almost eight times that of sample S1.

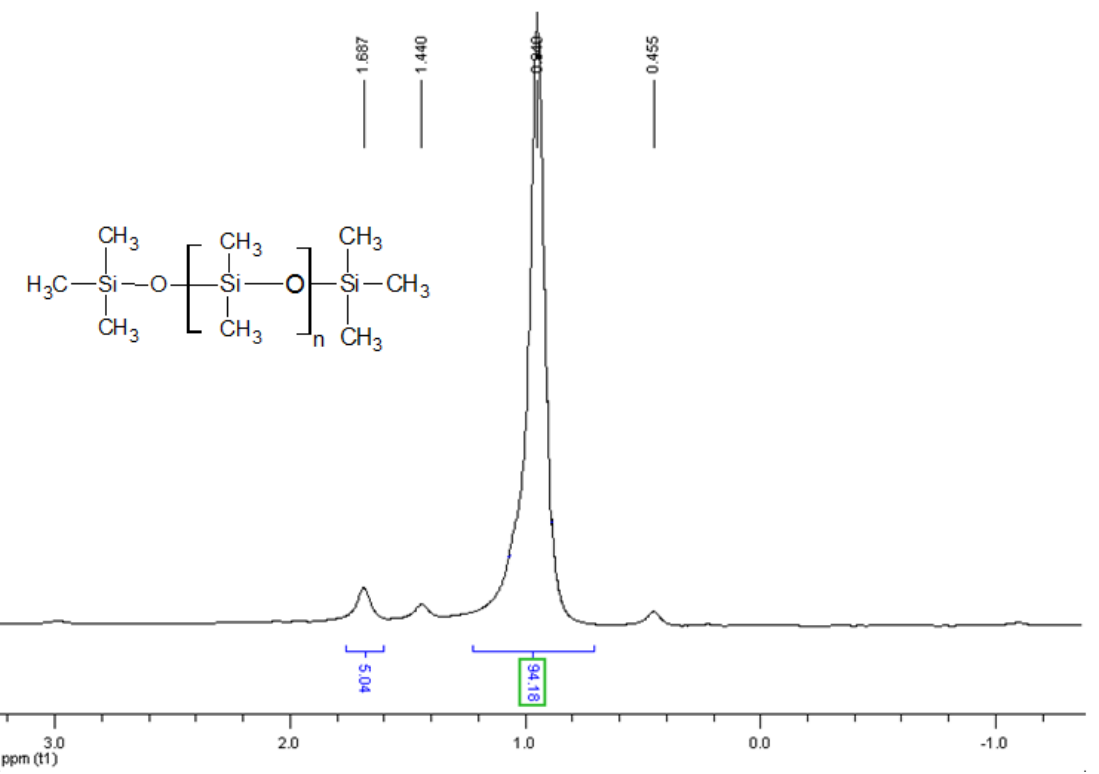

Figure 1. ${ }^{13} \mathrm{C}$-Nuclear magnetic resonance spectrum of S1 sample (structure shown in insert). 
Table 1. Chemical composition, density and viscosity of the crude oil samples.

\begin{tabular}{l|c|c|c|c|c|c|c|c}
\hline \multicolumn{1}{c|}{ SARA } & Unit & Oil 1 & Oil 2 & Oil 3 & Oil 4 & Oil 5 & Oil 6 & Oil 7 \\
\hline Density & ' API & 13.2 & 21.2 & 24.0 & 26.3 & 27.4 & 28.0 & 28.2 \\
\hline Viscosity & cP & 1200.0 & 200.0 & 53.0 & 25.0 & 15.0 & 7.6 & 5.0 \\
\hline Saturated hydrocarbons & $\mathbf{w t \%}$ & 35.7 & 40.7 & 47.1 & 45.0 & 32.1 & 39.6 & 27.9 \\
\hline Total aromatic hydrocarbons & $\mathbf{w t \%}$ & 24.6 & 34.1 & 29.3 & 37.0 & 40.1 & 38.9 & 40.0 \\
\hline Resins & $\mathbf{w t \%}$ & 32.4 & 22.8 & 22.3 & 15.0 & 21.1 & 20.4 & 26.9 \\
\hline Asphaltenes & $\mathbf{w t \%}$ & 7.3 & 2.4 & 1.3 & 3.0 & 6.7 & 1.1 & 5.2 \\
\hline
\end{tabular}

Sample S3 appeared to be a macromolecule with a very high polymerization degree because the ${ }^{13} \mathrm{C}$-NMR spectrum showed only one intense signal, located at $0.940 \mathrm{ppm}$. In this case, because it has a long polymer chain, the methyl groups at the ends are diluted as a function of the low molar ratio (terminal group effect), so it is more probable that the signal was not detected by the device, or it coalesced with the signal of the methyl groups of the repeated unit. Therefore, it was not possible to calculate the polymerization degree or molar mass of this sample, but these values are known to be much higher than those of sample S2 $(n=447)$.

The ${ }^{13} \mathrm{C}-\mathrm{NMR}$ analysis of the Solbrax Eco solvent showed various signals coalescing in a single chemical shift range (between 11 and $39 \mathrm{ppm}$ ). The reason is that Solbrax is a mixture of hydrocarbons with very similar structures. This range contains the chemical shifts of the ${ }^{13} \mathrm{C}$ atoms of hydrocarbons with linear or branched chains (Silverstein et al., 1991). Also, the chemical shifts of the $\mathrm{CH}_{2}$ groups in monocyclic alkanes (from $\mathrm{C}_{3} \mathrm{H}_{6}$ to $\mathrm{C}_{10} \mathrm{H}_{20}$ ) can be observed from 22 to $28 \mathrm{ppm}$.

The presence of other compounds, such as alkanes, aromatics or heteroatoms, was not detected. Nevertheless, these may be present in very small quantities, based on the device's sensitivity ( 1\%).

Table 1 shows the characterization of crude oil samples. The SARA method indicates the levels of saturated hydrocarbons (S), aromatics (A), resins $(\mathrm{R})$ and asphaltenes $(\mathrm{A})$ present in the oil. Table 1 also shows the density and viscosity values of each oil sample.

The results obtained show that crude oil 1 has the highest content of asphaltenes and resins, crude oils 5 and 7 have the highest aromatic contents and crude oil 3 has the highest level of saturated hydrocarbons.

The densities of the oil samples were expressed as API grade ( $\left.{ }^{\circ} \mathrm{API}\right)$, according to the scale defined by the American Petroleum Institute to describe and classify crude oils based on their specific gravity, measured at $15.6^{\circ} \mathrm{C}$. The specific gravity is inversely proportional to the ${ }^{\circ} \mathrm{API}$ density, so lighter oils have higher API grades (Mothé et al., 2008). The oils were numbered in ascending order of ${ }^{\circ} \mathrm{API}$ values.

\subsection{Testing the efficiency of the additives as antifoams}

\subsubsection{Effect of condition variations}

Initially, the tests were carried out with the purpose of verifying foam formation in oil sample 2. After that, the foam formation tests were performed with the other oil samples, with or without additives, in the preselected conditions.

Foam formation in the oil sample 2 was assessed by varying one condition at a time, as in the following tests: air pressure for the foam formation (Figure 2); temperature used in the tests (Figure 3) and conditioning time in the oven (Figure 4). Each condition was varied, while all others remained constant.

It can be observed that the conditioning time does not affect formation and breakdown of foam (Figure 4). On the other hand, at lower pressures the formation of foam is impaired, but no alteration was observed in the amount of time required to the total breakdown of foam formed (Figure 2). Also, since the oil viscosity decreases with increasing temperature, the formation of foam is initially enhanced at lower temperatures, 
but breaks down more quickly with time due to stronger draining that occurs in the so-called Plateau channels (Figueiredo et al., 1999).

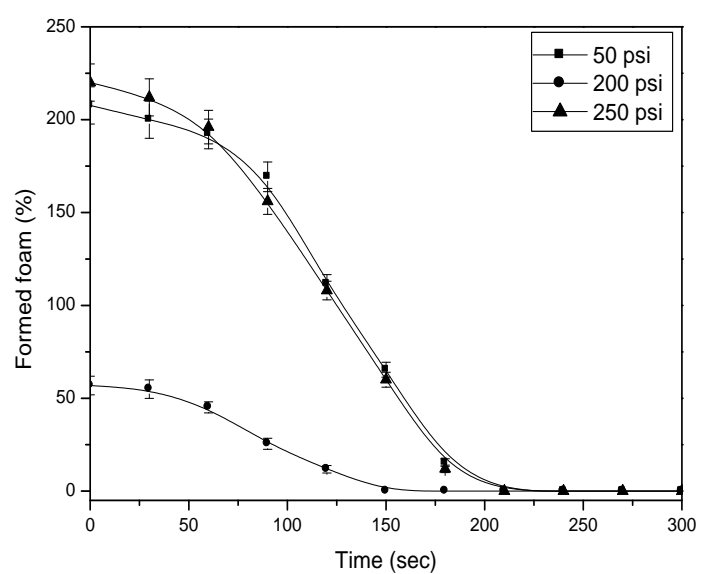

Figure 2. Percentage of foam formed on crude oil sample 2 as a function of time, submitted to different pressures, at $60^{\circ} \mathrm{C}$ and conditioning time of one hour.

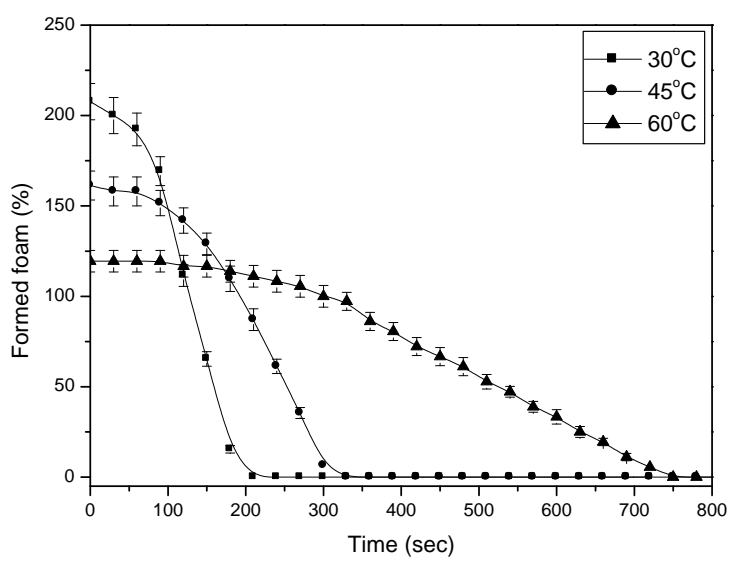

Figure 3. Percentage of foam formed on crude oil sample 2 as a function of time, in different temperatures, at 200 psi and conditioning time of one hour.

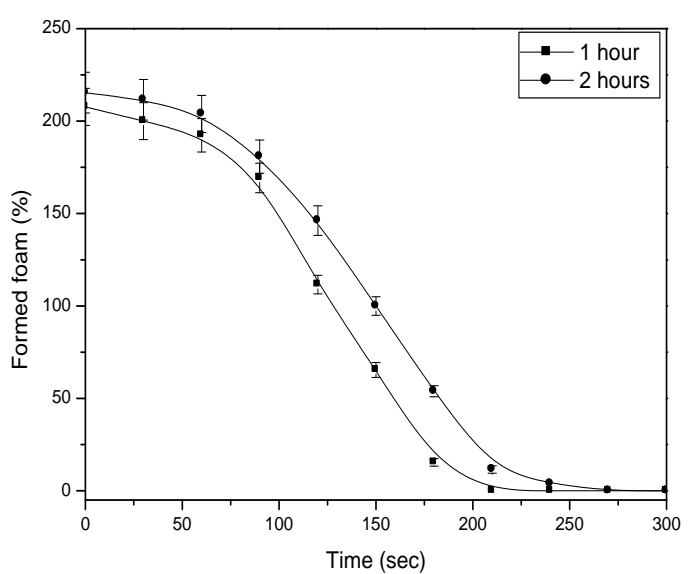

Figure 4. Percentage of foam formed on crude oil sample 2 as a function of time, submitted to different conditioning times, at $60^{\circ} \mathrm{C}$ and 200 psi.
From the results obtained in these tests, the following conditions to carry out other foam formation and breakdown assays were selected: time of conditioning of $1 \mathrm{~h}$ (shortest time); air pressure of $200 \mathrm{psi}$ (the lowest pressure at which a good foam level was obtained) and temperature of $60{ }^{\circ} \mathrm{C}$ (at which the largest volume of foam is also generated). The results of the foaming tests with the other six oil samples are shown in Figure 5.

As observed in an earlier study (Poindexter et al., 2002), which was carried out with another testing method, the viscosity of the oils appeared to be the most important factor influencing foam formation. Crude oil 1 , with the highest viscosity (Table 1), did not produce any foam, even though it contains the highest levels of foam-stabilizing species (resins $=32.4 \mathrm{wt} \%$ and asphaltenes $=7.3$ wt\%, Table 1).

On the other hand, crude oil 6 only generated a small volume of foam, with low stability, facilitating drainage of the liquid. It contains small amounts of asphaltenes (1.1 wt\%) and resins (20.4 wt\%). The foam formed in crude oil 7 was even less stable. Although it contains more asphaltenes than crude oil 6 , it is less viscous.

Among the oils tested, samples 3,4 and 5 provided the highest foam formation percentage. Crude oil 5 has a higher amount of foam-stabilizing species than crude oils 3 and 4, although, in comparison with these samples, the oil sample 5 presented the lowest viscosity (Table 1 ). This fact may have contributed to this sample being third in the stability test.

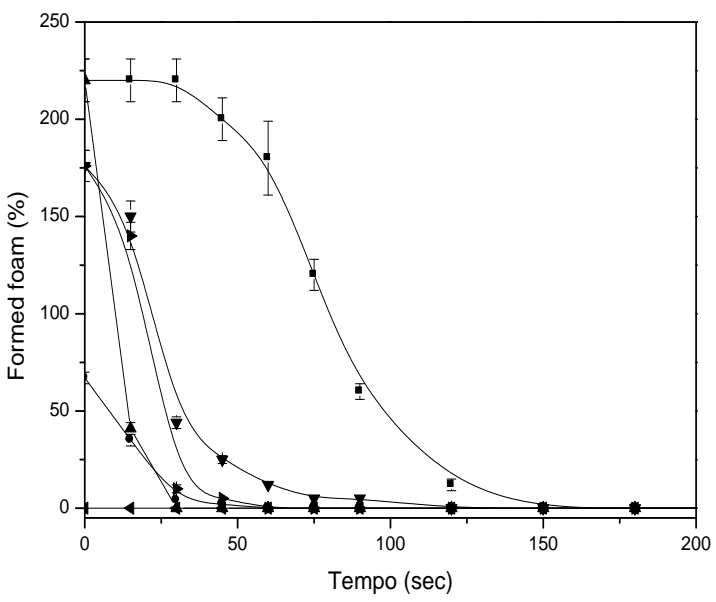

Figure 5. Percentage of foam formed on the crude oil samples as a function of time: (4) crude oil 1; ( $\mathbf{a})$ crude oil 3; ( $\nabla)$ crude oil 4; ( ) crude oil 5; (•) crude oil 6 and $(\boldsymbol{\Delta})$ crude oil 7. 


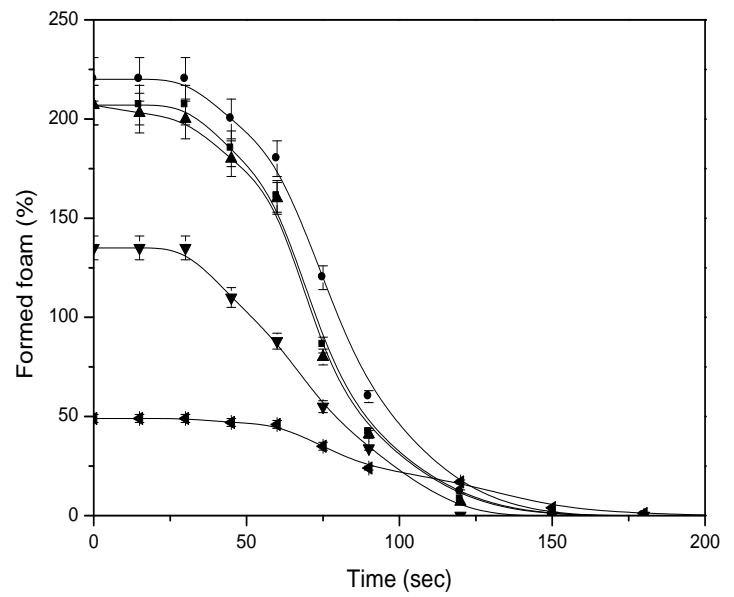

Figure 6. Efficiency tests of the silicone solutions as antifoaming additives in samples of crude oil $3:(\bullet)$ crude oil, ( $\mathbf{\square})$ crude oil + solbrax solvent, $(\boldsymbol{\Delta})$ crude oil + S1 solution, $(\boldsymbol{\nabla})$ crude oil + S2 solution and $(\mathbf{4})$ crude oil + S3 solution.

By comparing the results for crude oils 3 and 4 , it was observed that the foam formed with the previous sample was more stable. Although crude oil 3 has a lower level of asphaltenes than crude oil 4 (Table 1), it has higher levels of resins and saturated hydrocarbons, making it slightly more viscous. From the results obtained, crude oils 3 and 4 were chosen to test the antifoam additives in subsequent assays.

\subsubsection{Effect of additives}

In these tests, solutions of the additive samples in the Solbrax solvent have been prepared at concentrations of $30 \% \mathrm{wt} / \mathrm{vol}$, which is the normal active material content in the antifoam formulations used in water-oil-gas separation tanks. Aliquots of these formulations were added to the crude oil samples so that the final additive

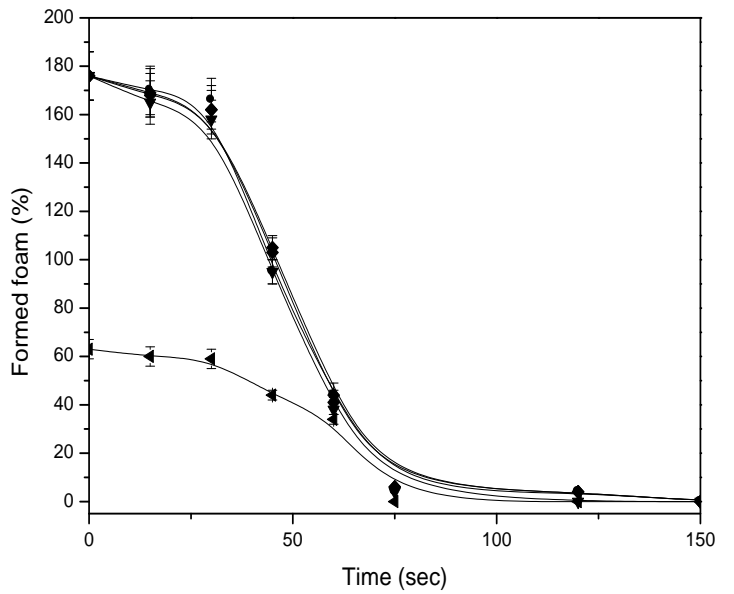

Figure 7. Efficiency tests of the silicone solutions as antifoaming additives in samples of the crude oil 4:

$(\bullet)$ crude oil, (घ) crude oil + Solbrax solvent, $(\boldsymbol{\Delta})$ crude oil + S1 solution, $(\boldsymbol{\nabla})$ crude oil + S2 solution and $(4)$ crude oil $+\mathrm{S} 3$ solution.

concentration in the oil was $40 \mathrm{ppm}$.

To evaluate the ability of the Solbrax in breaking down the foam, initially the tests were performed with only this solvent added, at the same concentration of $40 \mathrm{ppm}$. Analyses have also been carried out with the silicone additives S1, S2 and S3, in crude oil 3. All results are shown in Figure 6. The Solbrax solvent has little influence on the foam stability, whilst the presence of silicone additives reduces the initial extent of formed foam, in the following descending order: S1 > S2 > S3. It is important to point out that the additive $\mathrm{S} 3$ has the highest viscosity and highest molar mass.

The literature (Callaghan et al., 1985) shows that most antifoams disperse well in the foaming solution. Nevertheless, there is normally a small amount of oil at the solution's surface along with small droplets of the solution, and the quantity of

Table 2. Surface tension of crude oil samples.

\begin{tabular}{|c|c|c|c|c|c|}
\hline \multirow[t]{2}{*}{ Crude oil } & \multirow[t]{2}{*}{$\begin{array}{l}\text { S.T. of crude oil } \\
\qquad\left(\mathrm{mN} \mathrm{m}^{-1}\right)^{\text {(a) }}\end{array}$} & \multirow[t]{2}{*}{$\begin{array}{l}\text { S.T. of crude oil + solvent } \\
\qquad\left(\mathrm{mN} \mathrm{m}^{-1}\right)^{(a, b)}\end{array}$} & \multicolumn{3}{|c|}{$\begin{array}{l}\text { S.T. of crude oil }+ \text { additive solution } \\
\qquad\left(\mathrm{mN} \mathrm{m}^{-1}\right)^{(a, c)}\end{array}$} \\
\hline & & & S1 & S2 & S3 \\
\hline Oil 3 & 29.6 & 28.4 & 23.5 & 23.0 & 23.8 \\
\hline Oil 4 & 30.0 & 29.2 & 23.5 & 23.5 & 23.8 \\
\hline \multicolumn{6}{|l|}{ Error $= \pm 0.1 \mathrm{mN} / \mathrm{m}$} \\
\hline \multicolumn{6}{|c|}{$\begin{array}{l}\text { Surface tension of pure Solbrax solvent: } 24.6 \mathrm{mN} / \mathrm{m} \\
\text { (a) } \mathrm{S} . \mathrm{T} .=\text { surface tension of the system; } \\
\text { (b) Values gotten with the addition of } 2 \mu \mathrm{L} \text { of Solbrax solvent in the crude oil } \\
\text { (c) Values gotten with the addition of } 2 \mu \mathrm{L} \text { of additive solution ( } 30 \% \mathrm{wt} / \mathrm{vol} \text { ) i }\end{array}$} \\
\hline
\end{tabular}


foam inhibitor at the surface is usually small as compared to the total amount of antifoam dispersed in the solution.

A comparison of the surface tensions (S.T.) of the oil-antifoam systems against those of the oils alone (Table 2) shows that the tensions decrease in the presence of antifoam agents and these values do not vary significantly. The silicone with intermediate viscosity (S2) had the greatest effect in reducing the surface tension. This behavior also indicates that the silicone with lowest molar mass (S1) may have been adsorbed at the oil surface, but was not able to inhibit foaming, i.e., there was not sufficient dispersion at the surface to break down the foam.

The intermediate molar mass of sample S2 made it less soluble in crude oil 3 than sample S1, and, in the case of sample S2, not only were the silicone molecules adsorbed at the oil-air interface, reducing the surface tension, but they were also dispersed in the oil, causing the breakdown of foam. The silicone sample with the highest molar mass (S3) had the greatest foam-inhibiting effect and the lowest adsorption at the oil-air interface, since it is the least soluble in the oil, forming a heterogeneous phase. With respect to the time of foam breakdown, the additive S3, with the highest molar mass and highest viscosity, took longer to work in crude oil 3 than the other additives.

Chaisalee et al. (2003) also showed that antifoam additives are initially deposited on the surface of the solution in the form of large oily drops. The compound is dispersed during agitation of the foaming solution, and this is greatly facilitated if the components diffuse well at the solution's surface. If the compound is highly viscous and/or does not diffuse well, its dispersion can be impaired and, as a result, the antifoam activity can decline. Therefore, the behavior observed with sample S3 can be attributed to its greater viscosity, which impaired its dispersion in the medium.

The additives were also tested in crude oil 4, which has a higher level of asphaltenes, that stabilize foam. The results are illustrated in Figure 7. The additive $S 3$ was efficient in breaking down the foam in oil 4 , but less so than in crude oil 3 . This behavior can be related to the higher content of foam-stabilizing species in crude oil 4. Moreover, sample S3 broke down the foam in crude oil 4 faster than in crude oil 3. In this case, the higher viscosity of crude oil 3 (compared to the viscosity of crude oil 4) probably hindered the dispersion of this additive.

\section{CONCLUSION}

The method of evaluating the breakdown of foam in oil by using the Aging Cell apparatus in a roller oven proved to be suitable. From the results obtained in this investigation, it was possible to conclude that oils with high viscosity did not generate foam, even when they had high levels of foam-stabilizing species (resins and asphaltenes). On the other hand, the oils with low viscosity had a low foam volume, and the foam had low stability, because the liquid was drained between the foam lamellae. Therefore, the viscosity of crude oils is a determining factor in predicting whether or not foam will form and, if so, how its stability will be affected over time.

The silicone samples performed satisfactorily in the efficiency tests, except for the sample with the lowest molar mass.

The antifoams were more efficient in crude oil 3 , which has a lower concentration of asphaltenes, than they were in crude oil 4 , because the foam inhibitors' molecules managed to act at the surface of the film and to penetrate it as well, forming a heterogeneous phase that was able to break down the foam. Hence, because crude oil 3 is more viscous, the additives' dispersion was hampered. The antifoam action at the oil surface was less efficient in crude oil 4, which has an asphaltene concentration nearly four times higher.

\section{ACKNOWLEDGMENTS}

We thank Research Center of PETROBRAS (CENPES) for donating the petroleum samples, Bluestar Silicones (Brazil) for donating the silicone samples, and Coordenação de Aperfeiçoamento de Pessoal de Nível Superior (CAPES), Conselho Nacional de Desenvolvimento Cientifico $e$ Tecnológico (CNPq) and Fundação de Amparo à Pesquisa do Estado do Rio de Janeiro (FAPERJ) for financial support. 


\section{REFERENCES}

ASTM International - Standards Worldwide . Método ASTM D 4052. Accessed on: < http://www.astm.org >. Accessed on: 6 april 2009.

Callaghan, I.C.; Mckechle, A.L.; Ray, J.E.; Walnwright, J. C. Identification of Crude Oil Components Responsible for Foaming. Society of Petroleum Engineers, p.171-188, 1985.

Chaisalee, R.; Soontravanich, S.; Yanumet, N.; Scamehorn, J.F. Mechanism of antifoam behavior of solutions of nonionic surfactants above the cloud point. Journal of surfactants and detergents. v. 6, n. 4 , p. 345- 351, out. 2003. doi:10.1007/s11743-003-0280-3

Chilingarian, G.V.; Robertson, J.O.; Kumar, S. Surface operations in petroleum production. Developments in Petroleum Science, v. 19A, n.3, p.59-69,1987.

Figueiredo, R.C; Ribeiro, A.L; Sabadini, E. Ciência de espumas: aplicação na extinção de incêndios. Química Nova, v.22, n.1, p. 126-130, 1999.

Mclean, J. D.; Spiecker, P. M.; Sullivan, A. P.; Kilpatrick, P.; Claridge, E. L.; Prats, M. A. Proposed Model and Mechanism for Anomalous Foamy Heavy Oil Behavior. SPE Paper 29243; Presented at the International Heavy Oil Symposium of the Society of Petroleum Engineers, p.19-21, 1995.

Mothé, C.G.; Junior, C.S. Petróleo pesado e utltrapesado - Reservas e produção Mundial. TN petróleo, n. 57, march 2008 (in portuguese).

Musser, B. J.; Kilpatrick, P.K. Molecular
Characterization of Wax Isolated from Variety of Crude Oils. Energy Fuels, v. 12, p.715-725, 1998. doi:10.1021/ef970206u

Pape, G.P. Silicones: Unique Chemicals for Petroleum Processing. Journal of Petroleum Thechnology, v. 35, n.7, p.1197-1204, 1983.

Poindexter, M. K.; Zaki, N.N.; Kilpatrick, P.K.; Marsh, S.C.; Emmons, D.H. Factors Contributing to Petroleum Foaming. 1. Crude Oil Systems. Energy \& Fuels, v. 16, p.700-710, 2002. doi:10.1021/ef010224i

Ramalho, J. B. V. S.; Lechuga, F. C.; Lucas, E. F.; Effect of the structure of commercial poly(ethylene oxide-b-propylene oxide) demulsifier bases on the demulsification of water-in-crude oil emulsions: elucidation of the demulsification mechanism. Quim. Nova, v.33, n.8, p.1664-1670, 2010. doi:10.1590/S0100-40422010000800009

Shaban, I. H. A study of foaming and carry-over problems in oil and gas separators. Gas Separation \& Purification, v. 9, n.2, p.81-86, 1995. doi:10.1016/0950-4214(95)93944-F

Silverstein, R. M.; Webster, F. X.; Kiemle, D.J. Identificação Espectrométrica de Compostos Orgânicos. 5a ed. São Paulo: LTC, 243-258 p (in portuguese).

Solbrax Eco Solvent - BR Distribuidora. Available at: < http://www.br.com.br/wps/portal/>. Accessed on: 12 june 2008 (in portuguese).

Szilas, A.P. Production and transport of oil and gas. Developments in Petroleum Science, v. 18B, p.68-69, 1986. 